\title{
The synthesis, molecular structure and spectra properties of sulfur and selenium deferiprone analogues
}

\author{
Waldemar Tejchman, ${ }^{\text {a* }}$ Ewa Żesławska, ${ }^{a}$ Krzysztof Zborowski, ${ }^{b}$ Wojciech Nitek, \\ and Marek $\dot{Z}$ ylewski ${ }^{c}$ \\ ${ }^{a}$ Department of Chemistry, Institute of Biology, Pedagogical University of Cracow, \\ ul. Podchorażych 2., 30-084 Kraków, Poland \\ ${ }^{b}$ Faculty of Chemistry, Jagiellonian University, ul. Ingardena 3, \\ 30-060 Kraków, Poland \\ ${ }^{c}$ Jagiellonian Center of Innovation, NMR Laboratory, ul. Bobrzyńskiego 14, \\ 30-348 Kraków, Poland \\ E-mail: waldek.tejchman@gmail.com
}

DOI: $\underline{\text { http://dx.doi.org/10.3998/ark.5550190.p009.262 }}$

\begin{abstract}
Deferiprone has a broad spectrum of biological effects. Thus it is interesting to investigate the influence of structural changes in deferiprone on its biological activity. This work presents a synthesis of a new selenium analogue of deferiprone, 3-hydroxy-1,2-dimethyl-4(1H)pyridineselenone (3-HDPSe), and an improved method for synthesis of a sulfur analogue of deferiprone, 3-hydroxy-1,2-dimethyl-4(1H)-pyridinethione (3-HDPT). The structures of the synthesized compounds were confirmed by means of IR, MS, ${ }^{1} \mathrm{H}$ NMR and ${ }^{13} \mathrm{C}$ NMR measurements. Single crystals of the selenium analogue were obtained and the crystal structure determined using X-ray diffraction. Additionally DFT (the B3LYP functional combined with the $6-311++\mathrm{G}^{* *}$ basis set) theoretical calculations were conducted and the results compared with experimental data.
\end{abstract}

Keywords: Deferiprone, selenodeferiprone, thiodeferiprone, Woollins' reagent, Lawesson's reagent, selenation

\section{Introduction}

Research on the application of 3-hydroxy-1,2-dimethyl-4(1H)-pyridinone, commonly known as deferiprone, started in R. Hider's laboratory in the 1980s. ${ }^{1}$ Deferiprone has a simple structure (Figure 1) and like other compounds in the group of 3-hydroxy-pyridin-4-ones has an $\alpha$ ketohydroxy fragment, which makes it a good chelating ligand capable of making complexes with various metal ions. 


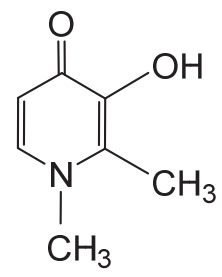

Figure 1. Chemical structure of deferiprone.

Some compounds found in plants have similar capabilities of chelating metal ions, among them are maltol, mimosine and 1,2-tropolone with structures similar to that of deferiprone. ${ }^{2}$ Due to its iron(III) ion chelation properties, deferiprone has been extensively studied and used in treating thalassemia in children ${ }^{3}$ and adults. ${ }^{4}$ Unlike desferrioxamine, which was used previously, deferiprone can be administered orally. ${ }^{5}$ However, deferiprone, despite some advantages, also has some side effects. ${ }^{6}$

Deferiprone is a good chelating agent not only for iron ions, but also ions of many other metals. It has been proved that $\mathrm{Ga}^{3+}, \mathrm{Al}^{3+}, \mathrm{In}^{3+}$ ions are strongly bound by deferiprone and with a similar potency. In the case of other metal ions there is the following dependency: $\mathrm{Cu}^{2+}>\mathrm{Zn}^{2+}>$ $\mathrm{Ca}^{2+}>\mathrm{Mg}^{2+}$. Deferiprone complexes with zinc are being investigated as a way to supplement the deficiency of this element in the human body. ${ }^{8}$

There is still a need to find new good lead(II) binding ligands. This metal is a highly potent pollutant, harming the environment and posing a health threat. The ability of lead(II) ions to replace zinc and calcium ions in metalloproteins deprives them of their metabolic functions. ${ }^{9}$ This is the reason why it is necessary to find ligands that would allow for selective removal of lead(II) ions. For this purpose, the sulfur analogues of maltol, 3-hydroxy-2-methyl-4-pyrone, and deferiprone, 3-hydroxy-1,2-dimethyl-4(1H)-pyridinone, were examined. These ligands form mononuclear complexes with $\mathrm{Pb}^{2+}$ and $\mathrm{Hg}^{2+}$ ions. The ratio of the ligands to the metal ions in the complexes was always $2: 1$. The most stable complexes among those investigated were examples where thiodeferiprone was used as ligand. ${ }^{10}$

The research conducted by Sarangi et al. proved that replacing sulfur with selenium in the ligands strengthens the binding with copper ions. ${ }^{11}$

Thus our group decided to make an attempt to obtain the selenium analogue of deferiprone and investigate its spectral characteristics. This would enable a comparison of metal complexes formed by deferiprone, thiodeferiprone and selenodeferiprone. We expected that the selenium deferiprone analogue would have comparable or even better capability to bind metal ions than deferiprone or its sulfur analogue.

The research we have conducted was focused on developing a new method to synthesise the 3-hydroxy-1,2-dimethyl-4(1H)-pyridinethione (3-HDPT, thiodeferiprone) and synthesizing the unknown 3-hydroxy-1,2-dimethyl-4(1H)-pyridineselenone (3-HDPSe, selenodeferiprone). (Figure 2). 
<smiles>Cc1c(O)c(=S)ccn1C</smiles>

3-HDPT<smiles>Cc1c(O)c(=S)ccn1C</smiles>

3-HDPSe

Figure 2. Chemical structures of thiodeferiprone and selenodeferiprone.

Previously, hydroxypyridinethiones were obtained from 3-hydroxy-1,2-dimethyl-4(1H)pyridinone by reaction with $\mathrm{P}_{4} \mathrm{~S}_{10}$ in solvent-free conditions. ${ }^{10}$ Chaves et al. used Lawesson's reagent (LR), but with a relatively poor reaction yield, ${ }^{12}$ possibly because they did not use a catalyst. In our work we have replaced the exocyclic oxygen atom with sulfur in deferiprone using Lawesson's reagent with hexamethyldisiloxane (HMDSO) as a catalyst under an inert gas.

There are few methods available to replace the exocyclic oxygen atom in heterocyclic compounds with selenium. ${ }^{13-16}$ Some require hydrogen selenide, which is highly toxic. In the case of many organic compounds it is possible to replace the oxygen atom by selenium using Woollins' reagent (WR). ${ }^{17}$ Woollins' reagent is a selenium analogue of the Lawesson's reagent. It allows the safe introduction of selenium. The reaction to replace oxygen with selenium was conducted in toluene under nitrogen and with HMDSO as a catalyst (Scheme 1).
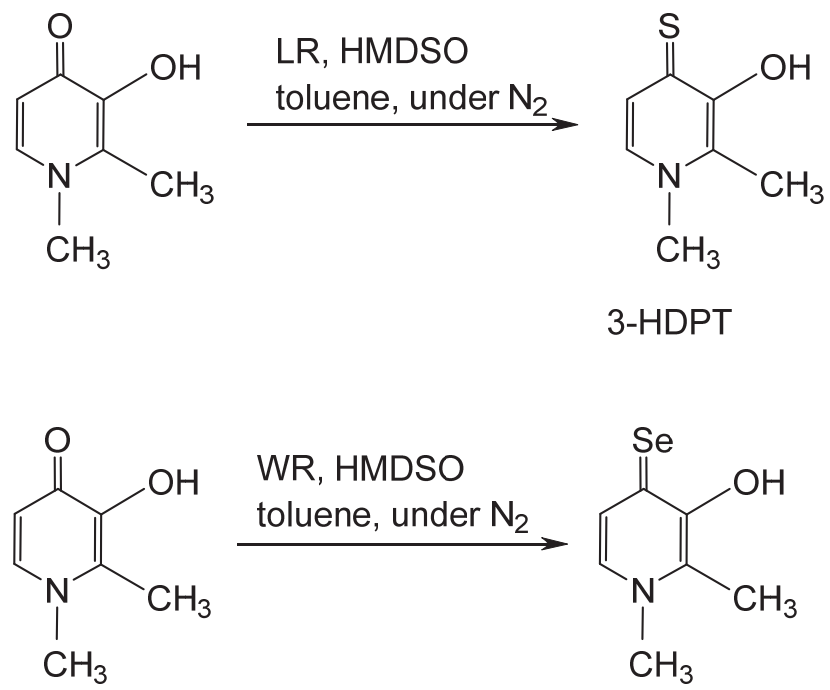

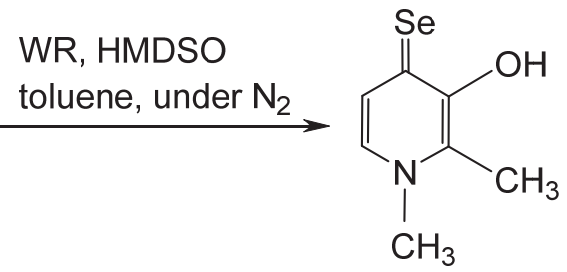

3-HDPSe

Scheme 1. Synthesis of thio- and selenodeferiprone.

An X-ray crystal structure analysis was carried out on the newly synthesized compounds 
and the molecular geometry was also studied with theoretical calculations. The results of these studies have been compared to the experimental data of structurally similar compounds found in the Cambridge Structural Database System. The theoretical NMR spectra were calculated and compared to the experimental data.

\section{Results and Discussion}

The mass spectra of the reaction products of the deferiprone thionation and selenation allows us to suggest that, in the measuring conditions, at temperature $280{ }^{\circ} \mathrm{C}$, in the gaseous phase thioand selenodeferiprone exhibit a tendency to form disulfide (3-HDPT-DIM) and diselenide (3-HDPSe-DIM) structures, as presented in Scheme 2.

The formation of such species for the sulfur deferiprone analogue was previously described by Monga et al. ${ }^{18,19}$ It was suggested that dimer formation is due to reaction with atmospheric oxygen in the presence of water. Because of considerable similarity between sulfur and selenium compounds we can assume that the same process occurs for the selenium analogue.

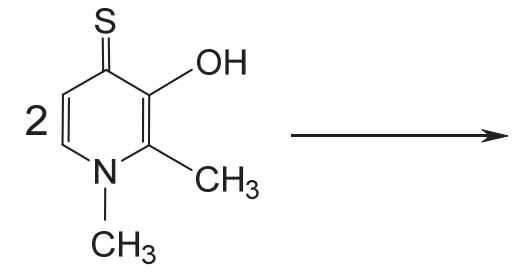

3-HDPT<smiles>Cc1c(O)c(=[Se])ccn1C</smiles>

3-HDPSe

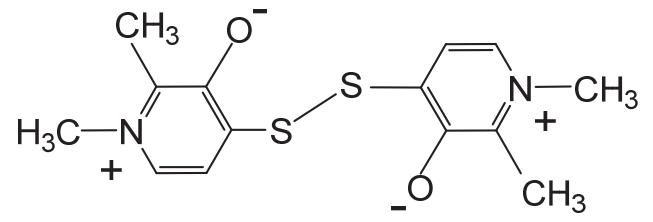

3-HDPT-DIM

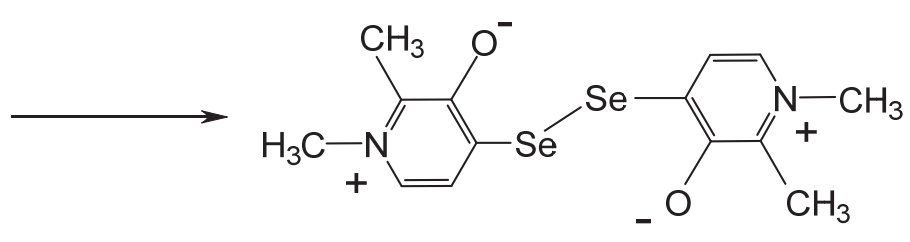

3-HDPSe-DIM

Scheme 2. Formation of disulfide and diselenide structures.

In the mass spectrum of the thionation reaction product there are two groups of peaks. One corresponds to the 3-HDPT structure, while the other to the 3-HDPT-DIM disulfide structure. The intensity of the 3-HDPT peak is five times higher then the intensity of that for 3-HDPTDIM. By the same token, there are two groups of signals present in the mass spectrum of the selenation reaction product, however the intensity of diselenide peak was higher. The intensity of the 3-HDPSe-DIM peak is twice the intensity of the 3-HDPSe peak. This suggests that the 
diselenide derived from deferiprone is more stable than the respective disulfide forms. This possibility will be subjected to further tests.

The X-ray analysis of a selenated deferiprone crystal demonstrated that in the solid-phase the compound exists as a diselenide, 3-HDPSe-DIM being a zwitterion (Figure 3).

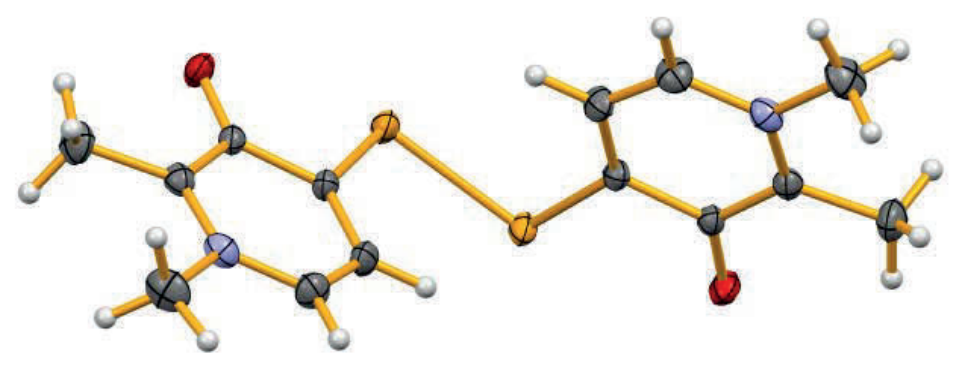

Figure 3. Molecular structure of 3-HDPSe-DIM.

The existence of only the dimer form of 3-HDPSe-DIM in the crystal is probably a result of the very long crystallization time and the type of the solvent used. For recrystallization a $96 \%$ ethanol solution was used. Slow evaporation of the solvent and the contact with air lasted two weeks. The oxidative conditions led to complete conversion of monomer into dimer.

An overview of the asymmetric unit of 3-HDPSe-DIM with the atom numbering scheme is shown in Figure 4.

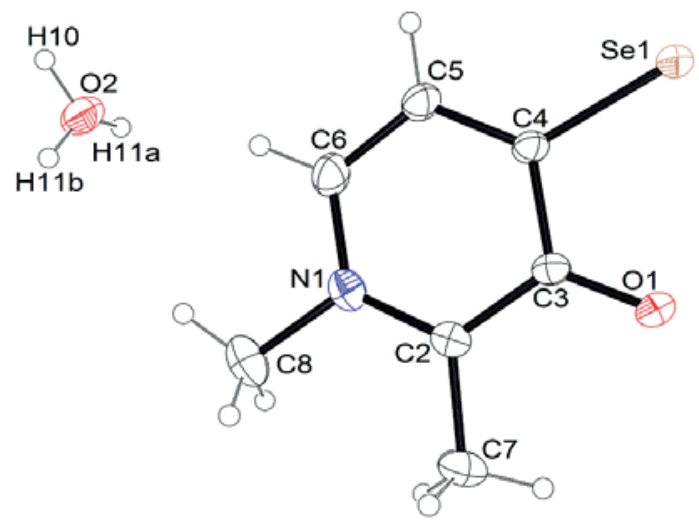

Figure 4. The asymmetric unit of 3-HDPSe-DIM with atom numbering scheme (displacement ellipsoids are drawn at the $50 \%$ probability level).

The crystals were monoclinic, the space group $\mathrm{C} 2 / \mathrm{c}$ and the unit cell consisted of four molecules of 3-HDPSe-DIM and eight molecules of water. The water molecules come from the solvent used for crystallization. An analysis of the geometry of diselenide moieties has shown the 
values of bond lengths, bond angles and torsion angles are typical values in the known structures of diselenides. To compare the selected values, we have analysed The Cambridge Structural Database (CSD, version 5.34, November 2012 update) in order to search for organic crystal structures containing the diselenide moiety. The histograms for 470 found structures are presented in Figure 5.

a)

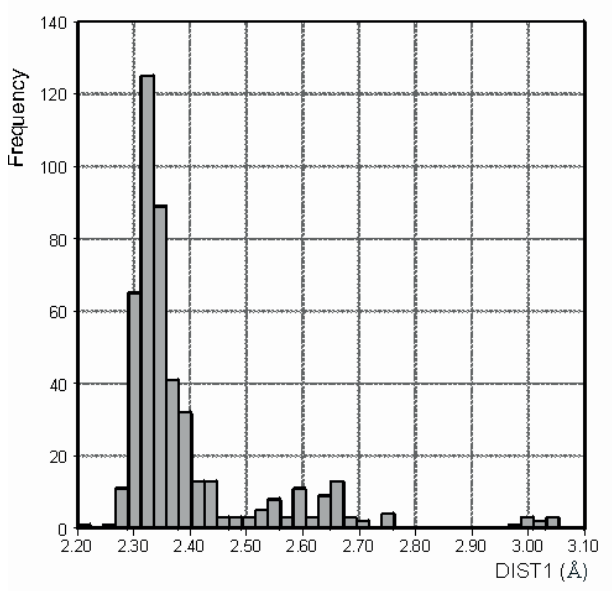

c)

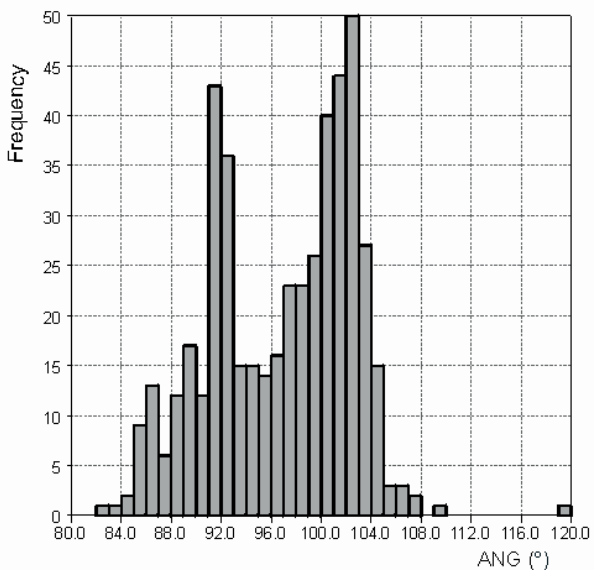

b)

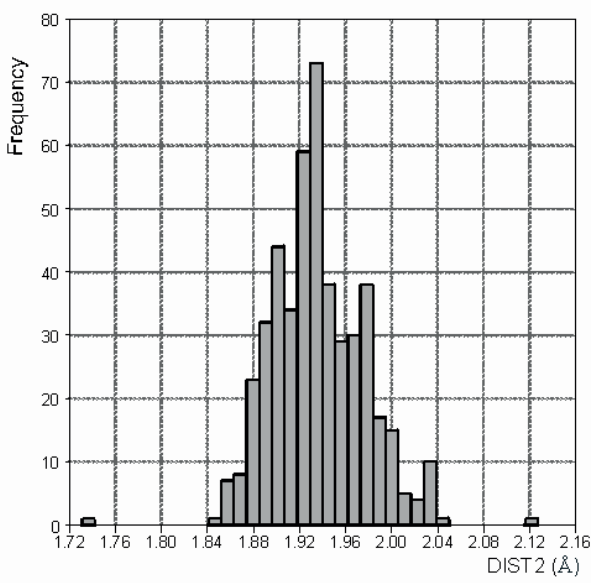

d)

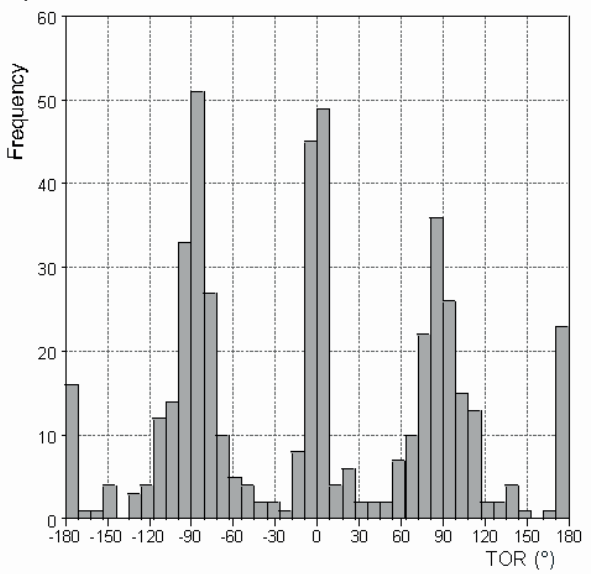

Figure 5. Statistical analysis of molecular fragments retrieved from Cambridge Structural Database:

a) Frequency histogram for DIST1: Se-Se bond lengths

b) Frequency histogram for DIST2: Se-C bond lengths

c) Frequency histogram for ANG: C-Se-Se bond angles

d) Frequency histogram for TOR: C-Se-Se-C torsion angles

The experimental Se-Se and Se-C bond lengths of HDPSe are $2.329 \AA$ (calculated $2.379 \AA$ ) and $1.902 \AA$ (calculated $1.923 \AA$ ) respectively. The average values for these bonds found in the previously known structures are $2.393 \AA$ and $1.936 \AA$ respectively (Fig.5a, 5b). The bond angle 
$101.8^{\circ}$ (Se-Se-C) (calculated $101.25^{\circ}$ ) is in agreement with the most frequently observed values for diselenide structures (Fig.5c). Also the torsion angle $-82.25^{\circ}$ (calculated $-88.54^{\circ}$ ) (C1-Se1Se1-C1) has the value of one of the four most often found ranges in the crystal structures (Fig.5d). The rms deviation for the atoms forming the plane of the six-membered ring (C1, N1, $\mathrm{C} 2, \mathrm{C} 3, \mathrm{C} 4, \mathrm{C} 5)$ is $0.0152 \AA$ with the maximum deviation of $0.023(1) \AA$ for $\mathrm{C} 3$, lying on one side of the plane, and $0.023(1) \AA$ for $\mathrm{C} 2$ lying on the other side. The typical length of the double bond between oxygen and carbon atoms is $1.22 \AA$, whereas for the single bond is $1.38 \AA$. The measured C3-O1 bond length of 1.273(3) $\AA$ corresponds to its intermediate binding character. The angle between the two planes of aromatic moieties in diselenide molecule is $76.88^{\circ}$.

The packing of the molecules of 3-HDPSe in the unit cell can be characterized by intermolecular interactions listed in Table 1.

Table 1. Intermolecular interaction for 3-HDPSe-DIM

\begin{tabular}{llllll}
\hline $\mathrm{D}-\mathrm{H} \cdots \mathrm{A}$ & $\mathrm{d}(\mathrm{D}-\mathrm{H})[\AA]$ & $\mathrm{d}(\mathrm{H} \ldots \mathrm{A})[\AA]$ & $\mathrm{d}(\mathrm{D} \ldots \mathrm{A})[\AA]$ & $<(\mathrm{DHA})\left[{ }^{\circ}\right]$ & Symmetry codes \\
\hline $\mathrm{O} 2-\mathrm{H} 10 \cdots \mathrm{O} 1$ & $0.84(4)$ & $1.91(4)$ & $2.740(2)$ & $174(4)$ & $\mathrm{x}+1 / 2, \mathrm{y}-1 / 2, \mathrm{z}$ \\
$\mathrm{O} 2-\mathrm{H} 11 \mathrm{~A} \cdots \mathrm{O} 2$ & $0.93(9)$ & $1.93(8)$ & $2.828(4)$ & $161(8)$ & $-\mathrm{x}+1,-\mathrm{y}-1,-\mathrm{z}$ \\
$\mathrm{O} 2-\mathrm{H} 11 \mathrm{~B} \cdots \mathrm{O} 2$ & $0.73(7)$ & $2.11(7)$ & $2.833(4)$ & $176(7)$ & $-\mathrm{x}+1, \mathrm{y},-\mathrm{z}-1 / 2$ \\
\hline
\end{tabular}

The molecule of 3-HDPSe-DIM makes only one type of the conventional hydrogen bond $(\mathrm{O}-\mathrm{H} \cdots \mathrm{O})$, formed by the phenolate oxygen atom of 3-HDPSe-DIM with the hydrogen atoms of water molecules. Each molecule of 3-HDPSe-DIM is connected with the neighbouring molecule of 3-HDPSe-DIM, via hydrogen bonds with three water molecules (Figure 6), forming the rings $R_{6}^{10}(28){ }^{20,21}$ The molecules of water build the chain along the $c$ axis. Each molecule of water forms one hydrogen bond with a molecule of 3-HDPSe and two hydrogen bonds with two other molecules of water (one hydrogen atom of water molecule in two positions with occupancy 0.5 ). 


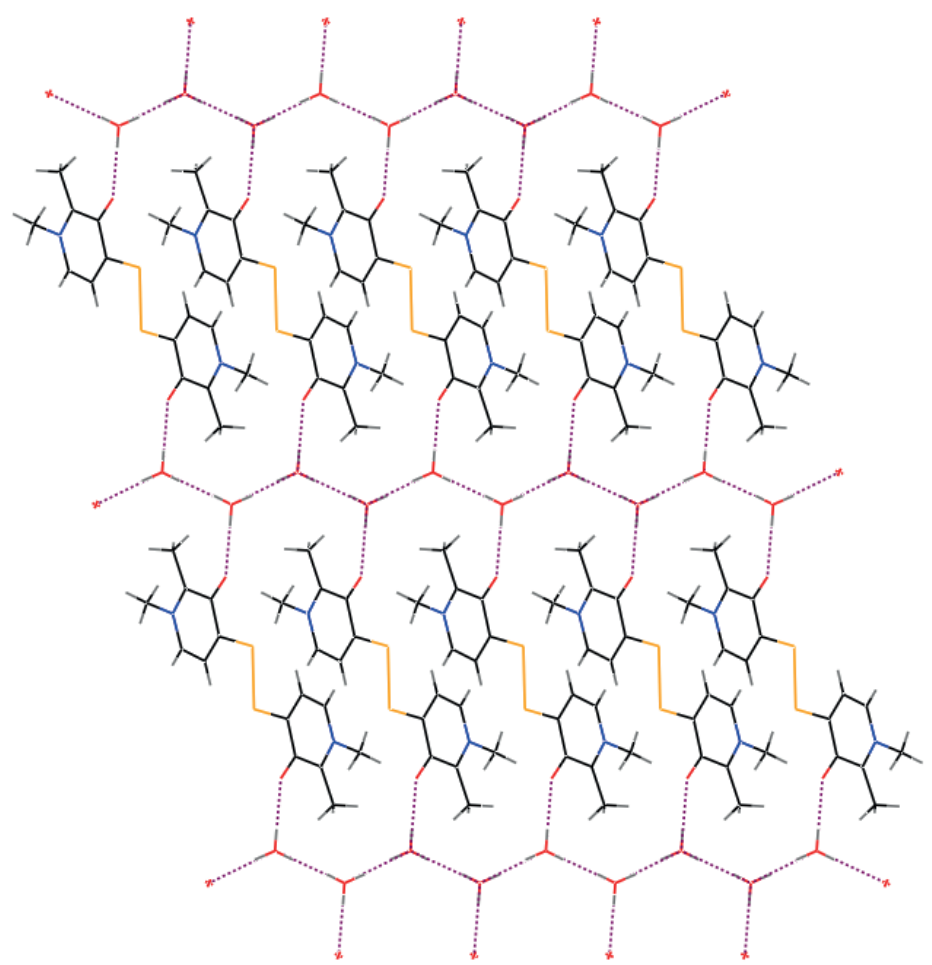

Figure 6. Partial packing view along [010] direction for 3-HDPSe-DIM (dashed lines indicate hydrogen bonds).

\section{NMR analysis}

The NMR analysis of both derivatives clearly shows the presence of only a monomeric form of molecules in solution. The ${ }^{1} \mathrm{H}$ NMR spectra of the compounds investigated contain characteristic broad signal of $\mathrm{OH}$ protons ( $\delta 6.8$ for thio and $\delta 8.5$ for a seleno derivative), whose presence is only possible for the monomeric form. Moreover, the chemical shifts of protons in the closest neighborhood of the nitrogen atom ( $\mathrm{N}$-methyl groups) are almost the same for both investigated compounds, indicating no differences between them in this fragment of molecule and thus supporting the lack of nitrogen atom ionisation for a seleno derivative in solution. Similar conclusions can be derived from the ${ }^{13} \mathrm{C}$ NMR spectra, in which only one set of signals for each derivative can be observed, with comparable chemical shifts. Minor changes can be attributed to the change of the sulfur atom to the selenium one in the carbonyl group.

Carbon and proton signals assignment was supported by HMBC and HSQC spectra analysis. Selenium spectrum shows only one signal $(\delta 246.67 \mathrm{ppm})$ indicating that there is only one population of selenium atoms. According to literature ${ }^{22}$ chemical shifts of selenium atoms in aromatic diselenides are greater than $400 \mathrm{ppm}$ whereas for selenocarbonyl group signals are spreaded over the whole range of selenium chemical shifts, depending on charge distribution and $\mathrm{C}=\mathrm{Se}$ bond polarization. The highest values of chemical shifts are observed for compounds where there is no possibility for increasing the electron density on selenium atom i.e. aliphatic 
selenoketones $(\delta>1600 \mathrm{ppm})$. Negative charge on selenium atom significantly increases shielding effect yielding lower chemical shift values. For selenodeferipron this can be achieved by the presence of second mesomeric form. Figure 7 .

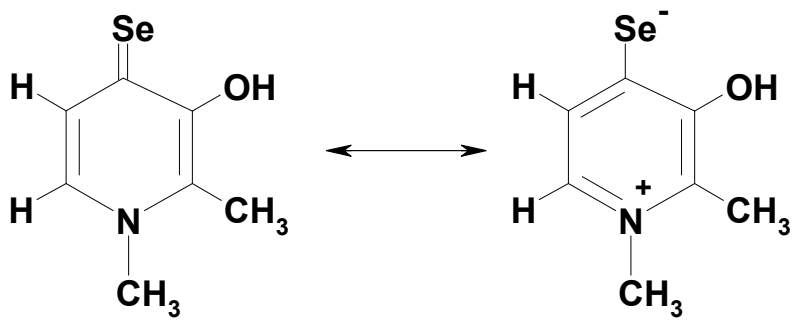

Figure 7. The second mesomeric form of selenodeferiprone.

This finding also can confirm the presence of selenodeferiprone in solution in only one monomeric form.

The comparison of the experimental and calculated chemical shifts in the NMR spectra for the monomeric forms of thio- and selenodeferiprone is presented in Figure 8.
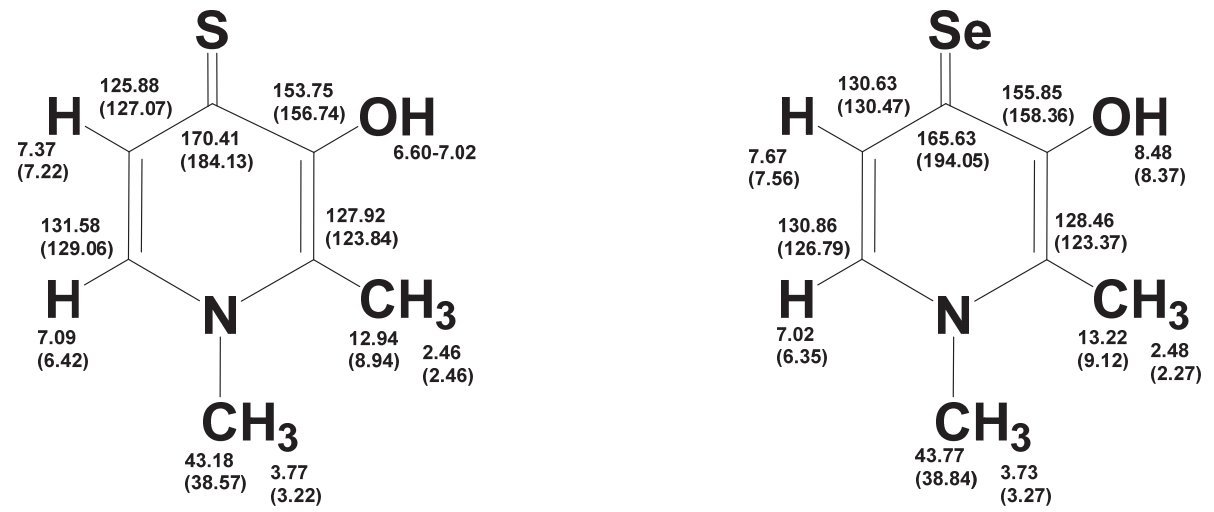

Figure 8. Chemical shift values in the ${ }^{1} \mathrm{H}$ NMR and ${ }^{13} \mathrm{C}$ NMR spectra for thio- and selenodeferiprone (calculated values in brackets).

In general, the calculated chemical shifts do not match the experimental values perfectly. However, small differences are reasonable on the employed level of theory. The overall consistency between the theoretical and the experimental chemical shifts support the above presented thesis of monomeric structures of the studied compounds in solution. The only significant discrepancy is observed for carbon atoms linked directly to the heavy sulfur (about 14 ppms) and especially selenium atoms (about $29 \mathrm{ppm}$ ). Such discrepancies can be clearly explained by so called "heavy atom effect on the light atom shielding", ${ }^{23,24}$ which is not included in the theoretical model used for our calculations. Similar difference between theory and 
experiment was observed previously for selenomaltol. ${ }^{16}$

\section{Experimental Section}

General. Lawesson's reagent used to obtain thiodeferiprone was synthesised according to the previously described procedure. ${ }^{25}$ Other reagents of analytical grade were supplied by Sigma Aldrich and used without further purification. Melting points (uncorrected) were measured on a Boetius apparatus. Elemental analyses were determined on the Elementar Analysensysteme GmbH, CHNS Vario Micro Cube. The IR spectra were recorded with a Jasco FT IR-670 Plus spectrophotometer as $\mathrm{KBr}$ disks. The NMR spectra were measured in $\mathrm{CDCl}_{3}$ on a Varian Mercury-VX 300 spectrometer operating at $300.08 \mathrm{MHz}\left({ }^{1} \mathrm{H}\right)$ and $75.46 \mathrm{MHz}\left({ }^{13} \mathrm{C}\right)$, the chemical shifts (ppm) referenced to lock the signal of the solvent, $J$ values are expressed in Hz. The NMR spectra of the selenoderivative were measured on Bruker Avance III HD spectrometer operating at $400.17 \mathrm{MHz}\left({ }^{1} \mathrm{H}\right)$. For the ${ }^{1} \mathrm{H}$ NMR spectrum, 16 scans were accumulated with spectral width of $6.4 \mathrm{kHz}$ and $32 \mathrm{k}$ data points. For ${ }^{13} \mathrm{C}$ NMR spectrum 1024 scans were acquired with spectral width of $24 \mathrm{kHz}$ and $65 \mathrm{k}$ data points. For the ${ }^{77} \mathrm{Se}$ spectrum 20512 scans were acquired with spectral width of $38 \mathrm{kHz}$ and $65 \mathrm{k}$ data points. The MS analyses were carried out on an AmaZon ETD mass spectrometer (Bruker Daltonics, Bremen, Germany). The MS settings for the experiments were as follows: flow rate was set to $3 \mu \mathrm{l} / \mathrm{min}$, heated capillary temperature was 280 ${ }^{\circ} \mathrm{C}$, capillary voltage was $4.5 \mathrm{kV}$. Scan parameters: scan range $100-1000 \mathrm{~m} / \mathrm{z}$, positive ionization mode. CID fragmentation was carried out in the ion trap analyzer with the aid of helium gas. The collision energy was set to ca. $1 \mathrm{~V}$. The samples were introduced into the mass spectrometer in a $\mathrm{CH}_{3} \mathrm{OH}: \mathrm{CHCl}_{3}$ 1:1 solution with $0.1 \% \mathrm{HCOOH}$.

Thiodeferiprone synthesis. The mixture of deferiprone $0.14 \mathrm{~g}(1.0 \mathrm{mmol})$, Lawesson's reagent $90.202 \mathrm{~g}, 0.5 \mathrm{mmol})$, and hexamethyldisiloxane (1.62 $\mathrm{g}, 10.0 \mathrm{mmol})$ were placed in toluene (25 $\mathrm{mL}$ ) and refluxed under $\mathrm{N}_{2}$ for $4 \mathrm{~h}$. Once heating was finished the solvent was removed in a vacuum evaporator and the dry residue was washed with petroleum. The solid obtained was crystallised from $\mathrm{CH}_{2} \mathrm{Cl}_{2}$. Yield $0.095 \mathrm{~g}, 61 \%$, mp $164-165{ }^{\circ} \mathrm{C}, \mathrm{MS}, \mathrm{m} / z, 311,[\mathrm{M}+1]^{+}$, $\left(\mathrm{C}_{14} \mathrm{H}_{18} \mathrm{~N}_{2} \mathrm{O}_{2} \mathrm{~S}_{2}\right)$ for 3-HDPT-DIM, 156, [M+1] ${ }^{+},\left(\mathrm{C}_{7} \mathrm{H}_{9} \mathrm{NOS}\right)$ for 3-HDPT, ${ }^{1} \mathrm{H}$ NMR (300 MHz, $\left.\mathrm{CDCl}_{3}\right) \delta$ ppm 7.09 (d, $\left.J=6.67 \mathrm{~Hz}, 1 \mathrm{H}, \mathrm{H}-6\right), 7.37$ (d, $\left.J=6.67 \mathrm{~Hz}, 1 \mathrm{H}, \mathrm{H}-5\right), 6.60$ - 7.02 (m, 1 $\mathrm{H}, \mathrm{OH}), 3.77\left(\mathrm{~s}, 3 \mathrm{H}, \mathrm{N}-\mathrm{CH}_{3}\right), 2.46\left(\mathrm{~s}, 3 \mathrm{H}, \mathrm{C}-\mathrm{CH}_{3}\right),{ }^{13} \mathrm{C} \mathrm{NMR}\left(75 \mathrm{MHz}, \mathrm{CDCl}_{3}\right) \delta \mathrm{ppm} 170.41$ $(\mathrm{C}=\mathrm{S}), 127.92$ (C-2), 131.58 (C-6), 153.75 (C-3), 125.88 (C-5), $43.18\left(\mathrm{~N}^{\left.-\mathrm{CH}_{3}\right),} 12.94\left(\mathrm{C}-\mathrm{CH}_{3}\right)\right.$, IR $\left(\mathrm{cm}^{-1}\right), 1618,1541,1498,1455,1378,1348,1273,1196(\mathrm{C}=\mathrm{S}), 1099,943,819,807,674$.

Selenodeferiprone synthesis. The mixture of deferiprone $(0.14 \mathrm{~g}, 1.0 \mathrm{mmol})$, Woollins' reagent (0.136 g, $0.256 \mathrm{mmol})$ and hexamethyldisiloxane (1.62 g, $10.0 \mathrm{mmol})$ were placed in toluene (20 $\mathrm{mL}$ ) and heated at under $\mathrm{N}_{2}$ for $2 \mathrm{~h}$. Once the heating had finished, the solution was filtered hot. After cooling, a yellow solid was obtained, which was recrystallized from EtOH. Yield $0.12 \mathrm{~g}$, $59 \%$, mp $179-180{ }^{\circ} \mathrm{C}$, Anal. Calc. for formula: $\mathrm{C}_{7} \mathrm{H}_{9} \mathrm{NOSe}$ C, 41.60\%, H, 4.49\%, N, 6.93\%, Found: C, 41.18\%, H, 4.39\%, N, 6.77\%, Anal. Calc. for formula: $\mathrm{C}_{14} \mathrm{H}_{18} \mathrm{~N}_{2} \mathrm{O}_{2} \mathrm{Se}_{2}: \mathrm{C}, 41.78 \%$, $\mathrm{H}$, 
3.98\%, N, 6.97\%, MS, m/z, 405, [M+1] $]^{+},\left(\mathrm{C}_{14} \mathrm{H}_{18} \mathrm{~N}_{2} \mathrm{O}_{2} \mathrm{Se}_{2}\right)$ for 3-HDPSe-DIM, 203, $[\mathrm{M}+1]^{+}$, $\left(\mathrm{C}_{7} \mathrm{H}_{9} \mathrm{NOSe}\right)$ for 3-HDPSe, ${ }^{1} \mathrm{H}$ NMR $\left(400 \mathrm{MHz}, \mathrm{CDCl}_{3}\right) \delta$ ppm 8.48 (br. s., $\left.1 \mathrm{H}, \mathrm{OH}\right), 7.02(\mathrm{~d}, J$ $=6.54 \mathrm{~Hz}, 1 \mathrm{H}, \mathrm{H}-6), 7.67(\mathrm{~d}, J=6.54 \mathrm{~Hz}, 1 \mathrm{H}, \mathrm{H}-5), 3.73\left(\mathrm{~s}, 3 \mathrm{H}, \mathrm{N}-\mathrm{CH}_{3}\right), 2.43(\mathrm{~s}, 3 \mathrm{H}, \mathrm{C}-$ $\left.\mathrm{CH}_{3}\right),{ }^{13} \mathrm{C}$ NMR $\left(100 \mathrm{MHz}, \mathrm{CDCl}_{3}\right) \delta$ ppm $165.63(\mathrm{C}=\mathrm{Se}), 128.48(\mathrm{C}-2), 130.86(\mathrm{C}-6), 130.63$ (C-5), $155.85(\mathrm{C}-3), 43.77\left(\mathrm{~N}_{-} \mathrm{CH}_{3}\right), 13.22\left(\mathrm{C}^{-} \mathrm{CH}_{3}\right),{ }^{77} \mathrm{Se}\left(76 \mathrm{MHz}, \mathrm{CDCl}_{3}\right) \delta \mathrm{ppm} 246.67, \mathrm{IR}$ $\left(\mathrm{cm}^{-1}\right), 1609,1540,1455,1362,1288,1269,1176,865$.

\section{X-ray analysis}

The crystals of the selenation product were obtained from ethanol by the slow evaporation of the solvent at room temperature. The yellow crystals appeared within two weeks. A single prismatic crystal of the selenation product suitable for the X-ray analysis was selected from the material prepared as described above. The intensity data were collected on the Bruker-Nonius Kappa CCD four circle diffractometer equipped with a Mo $(0.71069 \AA) \mathrm{K} \alpha$ radiation source. The crystal data, details of data collection and structure refinement parameters are summarized in Table 2.

Table 2. Crystal data and structure refinement for 3-HDPSe-DIM

\begin{tabular}{ll}
\hline Identification code & 3-HDPSe-DIM \\
\hline Empirical formula & $\mathrm{C}_{14} \mathrm{H}_{16} \mathrm{~N}_{2} \mathrm{O}_{2} \mathrm{Se}_{2} \cdot 2 \mathrm{H}_{2} \mathrm{O}$ \\
\hline Formula weight & 438.24 \\
\hline Temperature $[\mathrm{K}]$ & $293(2)$ \\
\hline Wavelength $[\AA]$ & 0.71073 \\
\hline Crystal system, & Monoclinic, \\
space group & $\mathrm{C} 2 / \mathrm{c}$ \\
\hline & $\mathrm{a}=15.1679(3)$ \\
& $\mathrm{b}=11.9535(2)$ \\
Unit cell dimensions & $\mathrm{c}=10.0256(3)$ \\
a, b, c $[\AA]$ & $\alpha=90$ \\
$\alpha, \beta, \gamma\left[{ }^{\circ}\right]$ & $\beta=112.673(1)$ \\
& $\gamma=90$ \\
\hline Volume $\left[\AA^{3}\right]$ & $1677.26(7)$ \\
\hline$Z$, Calculated density $\left[\mathrm{Mg} / \mathrm{m}^{3}\right]$ & $4,1.735$ \\
\hline Absorption coefficient $\left[\mathrm{mm}^{-1}\right]$ & 4.427 \\
\hline $\mathrm{F}(000)$ & 872 \\
\hline Crystal size [mm] & $0.65 \times 0.50 \times 0.23$ \\
\hline Theta range for data collection $\left[{ }^{\circ}\right]$ & 4.06 to 30.01 \\
\hline Reflections collected / unique & $16372 / 2450$ \\
\hline Max. and min. transmission & {$[\mathrm{R}(\mathrm{int})=0.1043]$} \\
\hline Data / restraints / parameters & 0.4292 and 0.1765 \\
\hline
\end{tabular}


Final R indices $[\mathrm{I}>2 \sigma(\mathrm{I})]$

$\mathrm{R} 1=0.0313$,

$\mathrm{wR} 2=0.0775$

Largest diff. peak and hole $\left[\mathrm{e} / \AA^{3}\right] \quad 0.661$ and -0.868

All non-hydrogen atoms were refined anisotropically using weighted full-matrix least-squares on $\mathrm{F}^{2}$. The hydrogen atoms involved in hydrogen-bonding were identified on the difference Fourier maps and refined with the geometrical restraints. All other hydrogen atoms bonded to carbons were included in the structure factor calculations at idealized positions. The structure was solved by direct methods using SHELXS and refined by SHELXL programs. ${ }^{26}$ For the molecular graphics ORTEP- $3^{27}$ and MERCURY programs ${ }^{28}$ were used.

\section{Computational details}

All theoretical calculations (geometries, NMR properties) were executed using the Gaussian'03 package. ${ }^{29}$ The B3LYP hybrid DFT-HF functional ${ }^{30}$ and the $6-311++\mathrm{G}^{* *}$ basis set $^{31}$ were chosen as the appropriate level of theory. Structural optimizations were followed by frequency calculations in order to confirm the minimum nature of the calculated geometries. The NMR properties were calculated using the GIAO method at the same computational level. ${ }^{32}$

\section{Conclusions}

The work presents the method of synthesis of the new compound, the selenium deferiprone analogue and the improved method of obtaining thiodeferiprone. Positive results were achieved using organophosphorus reagents. Lawesson's reagent (2,4-bis(4-methoxyphenyl)-2,4-dithioxo1,3,2,4-dithiadiphosphetane) was used to replace the oxygen atom with a sulfur atom and Woollins' reagent (2,4-diphenyl-1,3-diselenadiphosphetane-2,4-diselenide) to replace the oxygen atom with a selenium atom in deferiprone. The use of Lawesson's and Woollins' reagents allows the synthesis of thio- and selenodeferiprone safely and with good efficiency. Selenodeferiprone on contact with air is oxidized to the corresponding diselenide which was obtained as a solid. The diselenide units in the crystal are held together by hydrogen bonds through water molecules. In our opinion, the selenodeferiprone oxidation process to diselenide is very slow. The crystal growth took two weeks. It is possible that selenodeferiprone oxidized to diselenide at the time. The MS, IR, NMR and elemental analyses were conducted immediately after receiving the product, hence their results confirm the existence of selenodeferiprone.

The X-ray and NMR data were compared with calculated values. The geometry of 3-HDPSeDIM molecule determined on the basis of the X-ray analysis was in satisfactory concordance with the calculation results made using B3LYP/6-311++G** method. The chemical shift values in the ${ }^{1} \mathrm{H}$ NMR and ${ }^{13} \mathrm{C}$ NMR spectra calculated for monomers of thio- and selenodeferiprone are also generally in agreement with the experimental data. 


\section{Supplementary Information}

CCDC 967298 contains the supplementary crystallographic data for this paper. This data can be obtained free of charge from The Cambridge Crystallographic Data Centre via www.ccdc.cam.ac.uk/data request/cif.

\section{References}

1. Liu D. Y.; Liu Z. D.; Hider R. C. Clin. Hemat. 2002, 15, 327-328.

2. Hoffbrand A. V. Best Pract. Res. Clin. Hemat. 2005, 18, 299-317. http://dx.doi.org/10.1016/j.beha.2004.08.026

3. Choudry V. P.; Pati H. P.; Saxena A.; Malaviya A. N. Indian J. Pediatr. 2004, 71, 213-216. http://dx.doi.org/10.1007/BF02724272

4. Ayyub M.; Ali W.; Anwar M.; Waqar A.; Khan M. N.; Ijaz A.; Hussain T.; Hussain S. J. Ayub Med. Coll. Abbottabad. 2005, 17, 12-15.

5. Neufeld E. J. Blood 2006, 107, 3436-3441. http://dx.doi.org/10.1182/blood-2006-02-002394

6. Berdoukas V.; Bentley P.; Frost H.; Schnebli H. P. Lancet 1993, 341, 1088. http://dx.doi.org/10.1016/0140-6736(93)92443-W

7. Kushner J. P.; Porter J. P.; Olivieri N. F. Hematology 2001, 47-61. http://dx.doi.org/10.1182/asheducation-2001.1.47

8. Saghaie L.; Houshfar G.; Neishabor M. Iran. J. Pharm. Res. 2003, 3, 179-189.

9. Payne J. C.; Horst M. A.; Godwin H. A. J. Am. Chem. Soc. 1999, 121, 6850-6855. http://dx.doi.org/10.1021/ja990899o

10. Lewis J. A.; Cohen S. M. Inorg. Chem. 2004, 43, $6534-6536$. http://dx.doi.org/10.1021/ic0493696

11. Sarangi R.; Gorelsky S. I.; Basumallick L.; Hwang H. J.; Pratt R. C.; Stack T. D. P.; Lu Y.; Hodgson K. O.; Hedman B.; Solomon E. I. J. Am. Chem. Soc. 2008, 130, 3866-3877. http://dx.doi.org/10.1021/ja076495a

12. Chaves S.; Gil M.; Canario S.; Jelic R.; Romao M. J.; Trincao J.; Herdtweck E.; Sousa J.; Diniz C.; Fresco P.; Santos M. A. Dalton Trans., 2008, 1773 - 1782. http://dx.doi.org/10.1039/b717172b

13. Korohoda M. J. Pol. J. Chem. 1983, 57, 875-880.

14. Tejchman W.; Korohoda M. J. Pol. J. Chem. 1996, 70, 1124-1134.

15. Żylewska A.; Tejchman W.; Korohoda M. J.; Żylewski M. Heterocycles 2003, 60, 2749 2760. http://dx.doi.org/10.3987/COM-03-9865

16. Tejchman W.; Zborowski K.; Lasocha W.; Proniewicz L. M. Heterocycles 2008, 75, 19311942. 
http://dx.doi.org/10.3987/COM-08-11337

17. Fitzmaurice J. C.; Williams D. J.; Wood P. T.; Woollins J. D. J. Chem. Soc., Chem. Commun. 1998, 741-743.

18. Monga V.; Patrick B. O.; Orvig C. Inorg. Chem. 2005, 44, 2666 - 2677. http://dx.doi.org/10.1021/ic048693y

19. Monga V.; Thompson K. H.; Yuen V. G.; Sharma V.; Patrick B. O.; McNeil J. H.; Orvig C. Inorg. Chem. 2005, 44, $2678-2688$.

http://dx.doi.org/10.1021/ic0486926

20. Etter M. C.; MacDonald J. C.; Bernstein J. Acta Crystallogr. B 1990, 46, 256-262. http://dx.doi.org/10.1107/S0108768189012929

21. Bernstein J.; Davis R. E.; Shimoni L.; Chang N. L. Angew. Chem., Int. Ed. Engl. 1995, 34, 1555-1573.

http://dx.doi.org/10.1002/anie.199515551

22. Duddeck H., Prog, Nucl. Mag. Res. Sp. 1995, 27, 1-323.

23. Kaupp M. Relativistic Effects on NMR Chemical Shifts in Relativistic Electronic Structure Theory II: Applications (Hrsg. P. Schwerdtfeger), series: Theoretical and Computational Chemistry, Elsevier, Amsterdam 2004, 552.

24. M. Kaupp M.; Buhl M.; Malkin V. G. Interpretation of NMR Chemical Shifts in Calculation of NMR and EPR Parameters. Theory and Applications, Wiley-VCH, Weinheim 2004, 3.

25. Lecher H. Z.; Greenwood R. A.; Whitehouse K. C; Chao T. H. J. Am. Chem. Soc. 1956, 78, 5018-5022.

http://dx.doi.org/10.1021/ja01600a058

26. Sheldrick G. M. Acta Crystallogr. A, 2008, 64, 112-122.

http://dx.doi.org/10.1107/S0108767307043930

27. Farrugia L. J. J. Appl. Crystallogr. 1997, 30, 565.

http://dx.doi.org/10.1107/S0021889897003117

28. Macrae C.F.; Edgington P. R.; McCabe P.; Pidcock E.; ShieldsP.; Taylor R.; Towler M.; van de Streek J. J. Appl. Crystallogr. 2006, 39, 453-457.

http://dx.doi.org/10.1107/S002188980600731X

29. Gaussian 03, Revision E.01, Frisch M. J.; Trucks G. W.; Schlegel H. B.; Scuseria G. E.; Robb M. A.; Cheeseman J. R.; Montgomery J. A. Jr.; Vreven T.; Kudin K. N.; Burant J. C.; Millam J. M.; Iyengar S.S.;Tomasi J.; Barone V.; Mennucci B.; Cossi M.; Scalmani G.; Rega N.; Petersson G. A.; Nakatsuji H.; Hada M.; Ehara M.; Toyota M.; Fukuda R.; Hasegawa J.; Ishida M.; Nakajima T.; Honda Y.; Kitao O.; Nakai H.; Klene M.; Li X.; Knox J. E.; Hratchian H. P.; Cross J. P.; Bakken V.; Adamo C.; Jaramillo J.; Gomperts R.; Stratmann R. E.; Yazyev O.; Austin A. J.; Cammi R.; Pomelli C.; Ochterski, J. W.; Ayala P. Y.; Morokuma K.; Voth G. A.; Salvador P.; Dannenberg J. J.; Zakrzewski V. G.; Dapprich S.;Daniels A.D.; Strain M.C.; Farkas O.; Malick D. K.; Rabuck A. D.; Raghavachari K.; Foresman J. B.; Ortiz J. V., Cui Q.; Baboul A. G.; Clifford S.A.; Cioslowski J.; Stefanov B. B.; Liu G.; Liashenko A.; Piskorz P.;Komaromi I.; Martin R. L.; Fox D.J.; Keith T.; Al-Laham M. A.; Peng C. Y.; 
Nanayakkara A.; Challacombe, Gill P. M.; Johnson B.; Chen W.; Wong M. W.; Gonzalez C.; Pople J. A. Gaussian, Inc., Wallingford CT, 2004.

30. Becke A. D. J. J. Chem. Phys. 1993, 98, 5648-5652. http://dx.doi.org/10.1063/1.464913

31. McLean A. D.; G. S. Chandler G. S. J. Chem. Phys. 1980, 72, 5639-5649.

32. Woliński K.; Hilton J. F.; Pulay P. J. Am. Chem. Soc. 1990, 112, 8251-8260. http://dx.doi.org/10.1021/ja00179a005 